\title{
BALLAST WATER POLLUTION RISK ASSESSMENT IN THE BLACK SEA
}

\author{
Vasile RAȚĂ, Liliana RUSU \\ -Dunarea de Jos\|l University, Faculty of Engineering, Galati, Romania \\ corresponding authors: vasile.rata@ugal.ro; liliana.rusu@ugal.ro
}

\begin{abstract}
Since the emergence of humanity, the marine environment has provided a safety net in many ways, has fostered socio-economic development, creating links between states, between continents. In the same time, it represents a priority source of food for a considerable percentage of the population. The same marine environment also creates solutions to current global problems, as a potential source of sustainable energy for the future. In recent decades, the stability of this ecosystem has been considerably shaken by the various types of pollution resulting from human activities. The Black Sea is not immune to these results from economic activities, such as the transport of goods by water, which creates the context for the migration of living organisms from one geographical region to another. The threat of ecosystems has been intensified by the process of globalization, by changing the natural food chains following the accidental introduction of nonindigenous marine life by discharging ballast water from ship tanks. Risk assessment to limit the effects of this biohazard problem is the first step in a normal regional chain of action..
\end{abstract}

Keywords: ballast water, Black Sea, pollution, shipping

\section{INTRODUCTION}

The importance of trade between states, regions and even continents over time has proved to be a real success, leading societies, where this process has taken place, to progress. At present the society, as we know it, is based on the commercial exchanges between countries, this tending to accentuate the volume of goods that are transported in the future. The most efficient way to achieve the transport of goods in large volumes and considerable distances is represented by the transport of goods by water. The transport of goods by water is known as the shipping industry.

In this sense, due to the evolution of the ship design and shipbuilding, the ballast system appeared, together with the ballast tanks. The ballast system is a technical solution implemented for all ships in general, but especially for commercial ships. The solution is used to compensate for the negative effects that occur if the ship sails, from a location, without cargo to a destination from where she will have to load the goods.

Ballast system has various effects on ships, as:

* adjust of the draft, mainly for propeller efficiency and secondly for ship height adjustments (if necessary),

* impact on ship stability,
* improvement of the trim of the ship (cost efficiency),

* improvement actions regarding ship structural stress.

Throughout history, the marine environment has provided several benefits to coastal communities and globally the economy try to adapt the development of technologies for it, especially to process the food that the planetary ocean offers to the Earth planet's population of over 7.5 billion inhabitants [1]. Specialists have to think and to offer solutions about the economic parameters that have increased by intensifying trade and the maritime transport of goods globally. At the same time, the marine environment is a sustainable source of energy for the future [2]. All this but not only, represents the benefits of the marine environment for human society.

In the context in which, the marine environment was affected by various types of pollution resulting from human activities as:

- shipping,

- offshore explorations/exploitations,

- fishing activities,

- cruising etc.

It is necessary first of all to evaluate the main generators of pollutants in different segments of their action [3-6], and then the impact of these pollutants 
on the marine environment. In this study will be evaluated the generic volume of potential hazardous ballast water which arrive in the targeted area by vessels, through their ballast water tanks.

\section{TARGET AREA}

The Black Sea is part of Planetary Ocean, represent approximately 4\% from Planetary Ocean [6]. It is situated between East of Europe, West of Asia and Caucasian Mountains. The Black Sea represent one of the seas which is considered an enclosed sea due to the shores which are representing more than $99 \%$ of its limits. In the same time, the Black Sea is not an endorheic basin because it communicates with Azov Sea, and also with the Planetary Ocean, through Marmara Sea.

The Black Sea is not immune to these, results from economic activities, which create the context for the migration of living organisms from one geographical region to another. The threat of ecosystems has been intensified by the process of globalization, by changing the natural food chains following the accidental introduction of nonindigenous marine life by discharging ballast water from ship tanks [3].
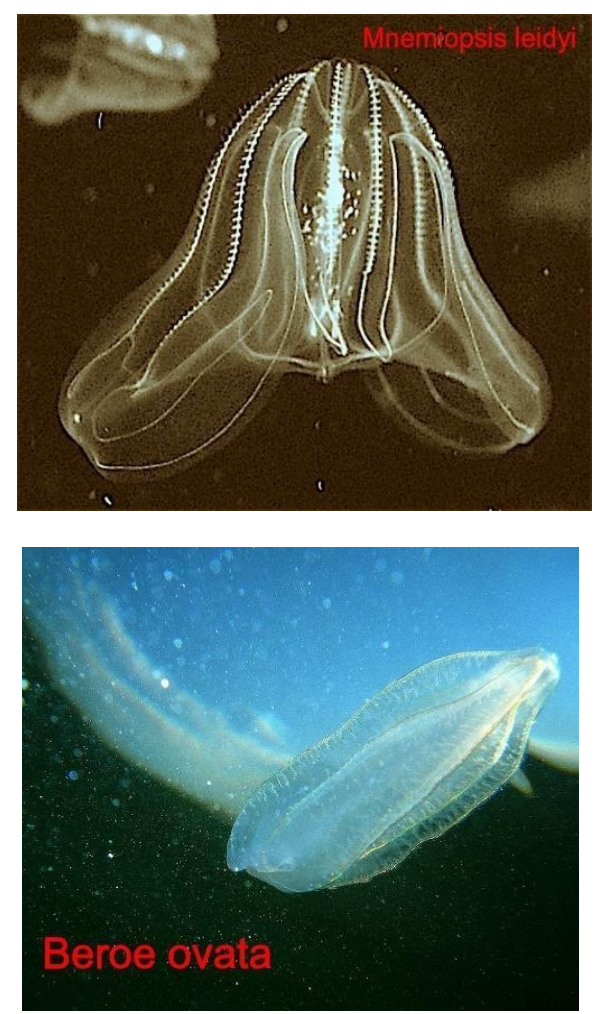

Fig. 1. Black Sea invasive species: Mnemiopsis leidyi/ Beroe ovata (processed from [7])

According to studies conducted so far [8-13], it has emerged that more than 29 species have accidentally arrived in the Black Sea, from different geographical areas. Two of these have had a considerable impact in the 1980s and 1990s, in the Black Sea. Thus, Mnemiopsis leidyi, Fig. 1 (up side) created an imbalance in the food chain, affecting the plankton population, which, by lack, affected fish and mammal species. This jellyfish was first time identified in the Black Sea in 1987 and its effects were visible in fishing industry decades. In fact, the situation was balanced by the appearance in the Black Sea of a natural predator of Mnemiopsis leidyi, namely the jellyfish Beroe ovata, Fig 1 (down side).

All those invasive species were accidentally introduced in the Black Sea by vessels, which were operated in different geographical areas. For example, those jellyfish mentioned above have origin in the North Atlantic. Those invasive species were introduced in the ballast tanks of commercial ships in the East Coast of North America, they travelled as ballast load few weeks till the ships arrived in one of the Black Sea harbours for load the contracted cargo. In the harbour, the ship should deballast entire or partial ballast water load in the same time of cargo loading. The deballasting process can be seen in Fig. 2.

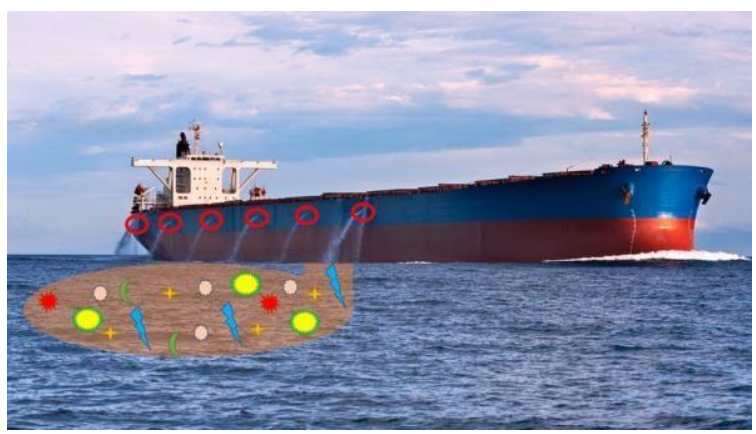

Fig. 2. Deballasting procedure on a commercial vessel (processed from [14])

Geographically, the main route of entry of potential species at risk of hazard into the Black Sea is the Bosporus Strait [15]. This statement is assumed because Bosporus Strait connects the Black Sea with the Sea of Marmara, and, by extension via the Dardanelles, the Aegean and Mediterranean seas, the Atlantic Ocean. As can be seen in Fig. 3, all shipping routes to the Black Sea are forced to cross the Bosporus Strait.

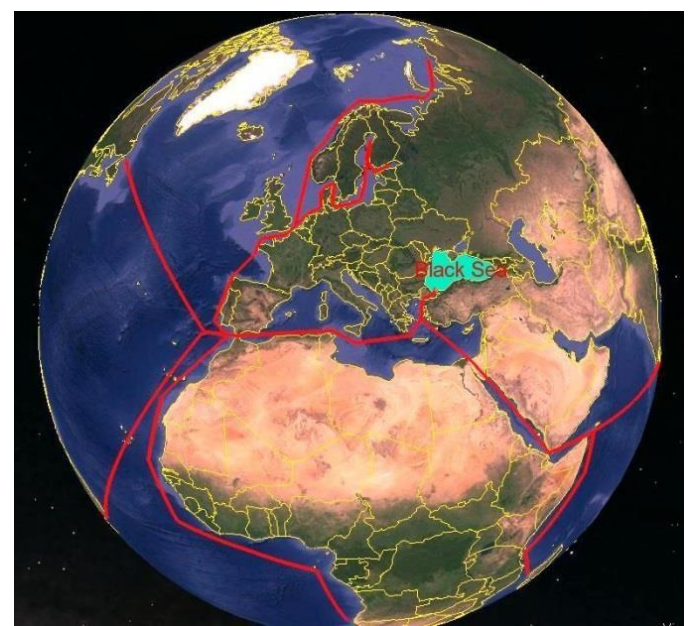

Fig. 3. Shipping routes to Black Sea, trough Bosporus Strait (processed from [16]) 
Even if the ships come through the Suez Canal from Asia (Far East or Middle East), Australia or East Africa, or if they pass the Gibraltar Strait coming from West Coast of Africa, North Europe, South or North America, whatever the origin of a seagoing ship, due to this geographical conditioning, it must cross the Bosporus Strait. In the same time, the Mediterranean Sea cannot be excluded, because of the possible inside harbours infected waters by a risk potential vessel that is deballasting near one ship ballasting and having next route to a Black Sea harbour.

All high risk potentially invasive species are passing the Bosporus Strait in the transit through Black Sea harbours, which are graphically marked with a yellow pin in Fig. 4. In the Black Sea, there are several important harbours, but if one takes into consideration all, there are more than fifteen. The most important that can be mentioned are Constanta, Novorossiysk, Odessa, Samsun. On the other hand, there are also harbours important for their countries, like Varna, Batumi, Trabzon, Tuapse, Taman.

\section{IMPACT EVALUATION}

In the context of an invasive species accidental insertion, most of the time, the harbours represented a hub of spreading. The infected water deballasted from vessels ballast water tanks in the roadstead area is carried by coastal currents, thus, having a significant spatial spread over time, similar with that in Fig. 5. Coupled with an alert rate of multiplication, can lead to unwanted situations in the marine environment in which they are accidentally introduced.

In order to understand the risks, this study evaluated the potential risk of introduction of new invasive species related to the shipping traffic in 2019. In this sense, an attempt was done to quantify the entire volume of water at risk by introducing invasive species into the Black Sea ecosystem, in the previous year.

In general, the ballast water capacity, as preliminary ship design, is following the below calculation formulas [17-18]:

$$
\begin{aligned}
& \mathrm{BW}=\frac{37.72}{100} \mathrm{DWT} \\
& \mathrm{DWCC}=\frac{94}{100} \mathrm{DWT} \\
& \mathrm{BW}=\frac{37.72}{94} \mathrm{DWCC}
\end{aligned}
$$

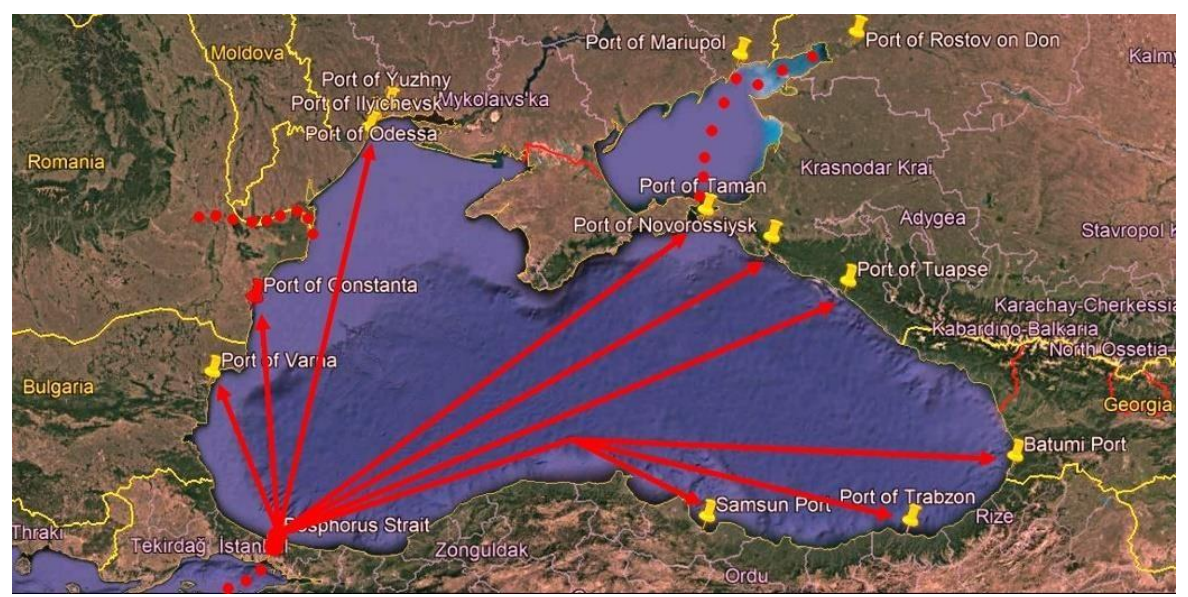

Fig. 4. Black Sea shipping routes from Bosporus Strait (processed from [16])

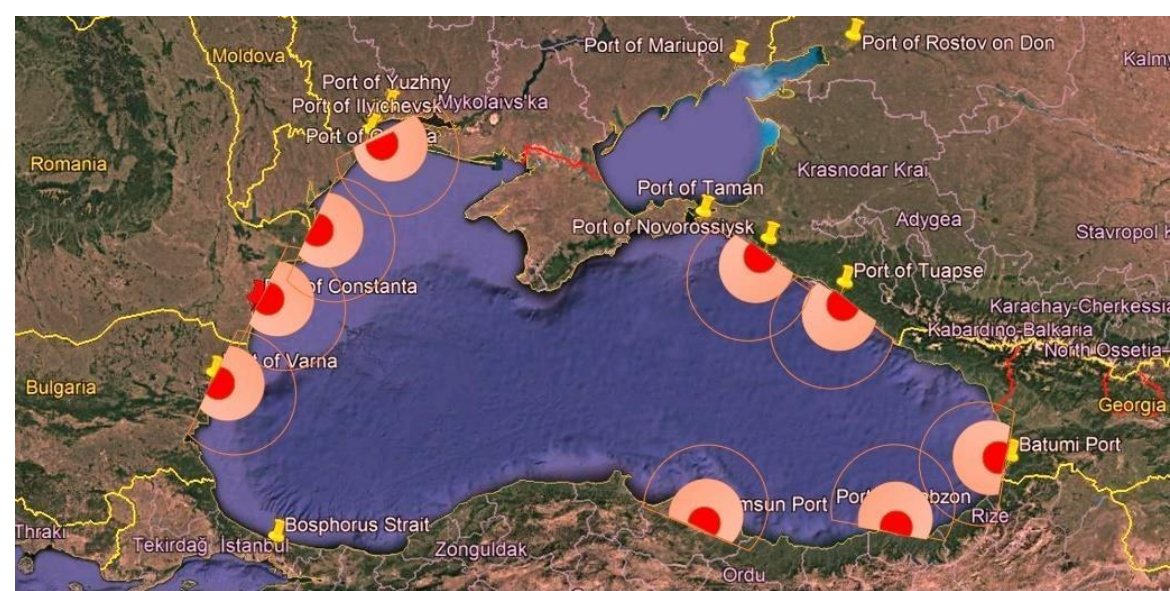

Fig. 5. Potential impact of invasive species arrived in the Black Sea harbors (processed from [15]) 
Table 1. Ships under ABS classification, randomly chosen

\begin{tabular}{|l|l|r|r|r|r|}
\hline \multicolumn{1}{|c|}{ Ship Name } & \multicolumn{1}{c|}{ Type } & Length $(\mathrm{m})$ & \multicolumn{1}{c|}{ Ballast $(\mathrm{t})$} & \multicolumn{1}{c|}{ DCWT $(\mathrm{t})$} & Percentage \\
\hline DIAMOND GAS ROSE & Gas Carrier & 293.5 & 64482.44 & 84380.1 & 76.4 \\
\hline AWTAD & Oil Carrier & 333 & 100952.2 & 345682.2 & 29.2 \\
\hline THALASSIC & Bulk Carrier & 224.9 & 38551.38 & 75863.7 & 50.8 \\
\hline CHARLOTTE MÆRSK & Container Carrier & 346.98 & 32001 & 80151 & 39.9 \\
\hline
\end{tabular}

The ballast water noted in formulas as (BW) indicates the volume in tones of water carried in the ballast tanks by ship. The deadweight was noted in formulas with (DWT) and means the cargo carrying capacity plus the sum weight of fuel, fresh water, ballast water, provisions, passengers and crew. Need to be mentioned that it does not include the weight of the ship itself.

At the same time, deadweight cargo capacity (DWCC) indicates just the cargo weight that can be loaded onboard, without fuel, fresh water, ballast water, provisions, passengers and crew.

Using the calculation gait (1) - (3) is resulting that the ballast water (BW) accounts for approximately $40 \%$ of the transported cargo (DWCC). This result is useful in the context of taking into consideration the assumption that all the ships are leaving fully loaded from the Black Sea harbors. This assumption represents an ideal scenario, which simplifies the calculation and it means that all ships are deballasting in the Black Sea ports entire ballast water from their ballast tanks.

On the other hand, the value extracted from the literature was verified using the public American Bureau of Shipping (ABS) database [19]. ABS is one of the world's leading ship classification organizations. As a method, there was selected several of commercial ships representative for the following categories: oil carrier, gas carrier, bulk carrier and container carrier.

It results, using the information from Table 1, that the average of ballast water (BW) capacity reported to deadweight cargo capacity (DWCC) is approximately $49 \%$ for those four ships. For the Gas Carrier and Bulk Carrier, there were used also the following parameters: 1 cubic meter of grains is equal with $790 \mathrm{Kg}$ [20], and for 11 of liquefied gas is equal with $0.51 \mathrm{Kg}$ [21].

Hydrocarbons, cereals, chemicals (fertilizers), coal, scrap metal and others are mainly exported from the Black Sea area. The shipping traffic in the Bosporus Strait has an ascending trend in the last years. In 2019, more than 41,000 vessels were passing the strait [22]. In this situation connected with the wish of development of the Black Sea neighboring countries, the context for risk of invasive species that could be inserted in the Black Sea will remain a long-term concern. All the neighboring countries should develop their ports [23], in order to maintain a competitive level from an economical point of view.

In this calculation, the deadweight cargo capacity (DWCC) will be a considered a fraction of total of gross tons of cargo passed through Bosporus Strait in 2019 , which sums up $638.9 \times 10^{6}$ tons, information arising from the literature [22]. But this value represents raw information that cannot be directly used in formulas because this value is summing both kinds of goods imports and also goods exports that passed the Bosporus Strait.

Also, it is necessary to do some assumptions because the ships may come to Black Sea world wide, so, in this calculation, the density of the water will be considered 1.024 tons per cubic meter.

The total ballast water that passes the Bosporus Strait in and out from the Black Sea is:

Total BW $=1.024 \cdot 638.9 \times 10^{6} \frac{{ }^{37.72}}{94}=262.5 \times 10^{6} \mathrm{~m}^{3}$

The value of $262.5 \times 10^{6}$ cubic meters represents the ballast water that passed the strait in both directions.

In order to calculate the volume of ballast water, which is threatening the environment of Black Sea, it was assumed the percentage between imports and export in 2019, from the most important harbour in the targeted area. In this sense, the public statistics of the port of Constanta for 2019 were considered [24].

$$
\begin{aligned}
& \frac{\text { Export }}{\text { Total (import }+ \text { export) }}=50.8 \% \\
& \mathrm{BW}=262.5 \times 10^{6} \cdot 0.508=133.34 \mathrm{~m}^{3}(6)
\end{aligned}
$$

The estimation of the ballast water potential risk in Black Sea in 2019 will be $133.34 \times 10^{6} \mathrm{~m}^{3}$. This value represents $2.43 \times 10^{-4}$ of the water volume of Black Sea.

\section{SOLUTIONS}

In the present, on the market, there are dozens of technical solutions that can be implemented in order to solve the issue of biological pollution, by preventing the marine organisms to migrate from a geographical area to another one. All these solutions are in an advance research and development stage. Technical solutions agreed by the authorities and institutions that are able to take such decisions or grant approvals can be consulted in Fig. 6. 


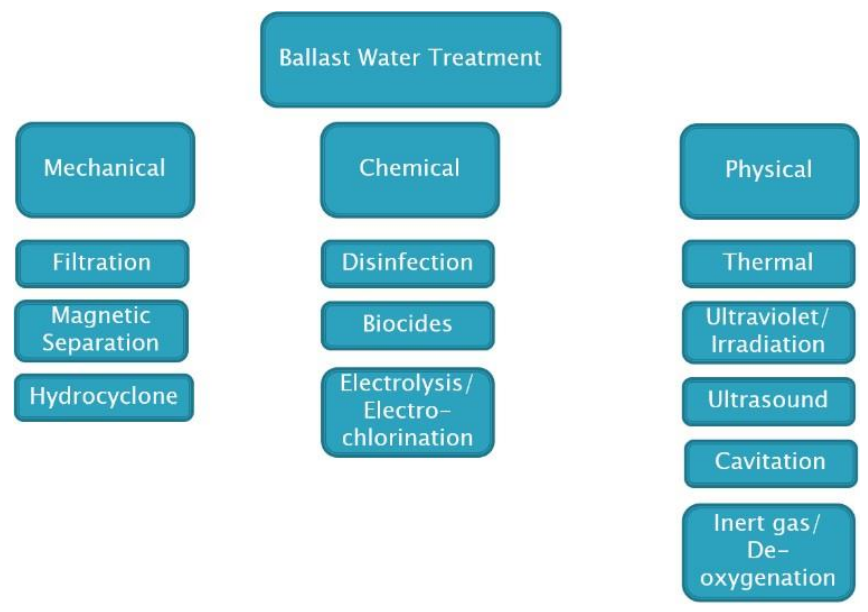

Fig. 6. Technical solutions available on the market

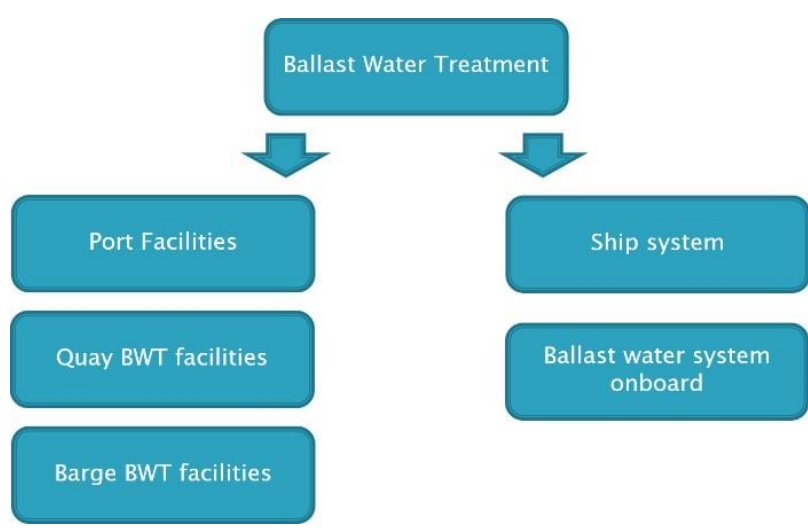

Fig.7. Facilities of fighting against bio-hazardous accidents

Today's problem is how to implement these solutions and, perhaps, the legislative considerations that require their implementation. This problem arises from the perspective of investments that need to be done in the direction of fleet renewal or modernization of the existing fleet. These investments are considerably large and no ship owner would be willing to incur such a cost in his business, because it hinders his economic activity through this financial effort that should be done. This solution is related to the right column in Fig. 7.

On the other hand, the majority of ship owners will prefer the solution of some port developments, like the ones presented in the left column in Fig. 7. This kind of approach can be found in the North Sea and Baltic Sea area [25].

This issue was actively debated in the past 10 years at global level, in the International Maritime Organization, in its competent departments [26]. The entry into force of the International Ballast Water Management Convention on 8 September 2017, IMO by its Marine Environment Protection Committee in the MEPC 71 reached a highly anticipated compromise agreement on the implementation dates for the so-called D-2 discharge standard [27]. As a conclusion to this in force requirement, all ships must implement a Ballast Water Management Plan in accordance with D-2 discharge standard until 8 September 2024.

\section{CONCLUSIONS}

Historical incidents with huge impact related to invasive species in the Black Sea in the past 50 years exist and they have been documented and studied.

The problem of ballast water is known and, at international levels, there are concrete measures that were enforced. Even so, three of six countries, including Romania, have not ratified the convention governing the ballast water issue.

In order to stay competitive in this field of activities, the Black Sea ports must develop itsself to help actively for increasing or maintaining the actual maritime traffic in the targeted area.

The solutions also exist not only as technical options, but also as market developed products. The main problem is to implement them because they are not cheap and to adopt the right philosophy which will be able to reduce the cost. In this regard, governments should facilitate funds directed to industry for this issue, opening more cost-effective lines of credit.

The responsible authorities should align their involvement and goals to international ones 
regarding pollution aspects of shipping as an economical segment.

\section{ACKNOWLEDGEMENT}

This work was carried out on the project ANTREPRENORDOC in the framework of Human Resources Development Operational Program 20142020, financed from the European Social Fund under the contract number 36355/23.05.2019 HRDOP/380/6/13 - SMIS Code: 123847.

\section{REFERENCES}

[1] World Development Indicators. Available online: http://datatopics.worldbank.org/worlddevelopment-indicators/ (accessed in May 2020)

[2] Rusu E., Onea F., 2018, Evaluation of the Shoreline Effect of the Marine Energy Farms in Differ-ent Coastal Environments. In: Proceedings of the 3rd International Conference on Advances on Clean Energy Research (ICACER 2018), Barcelona, Spain.

[3] Rata V., Gasparotti C, Rusu L., 2018, Ballast Water Management in the Black Sea's, Journal of Marine Science and Engineering, 6, 69, pp. 1-10

[4] Rata V., Rusu E., 2020, Can Air Quality be Influenced in Coastal Areas by Shipping?, Journal of Marine Science Volume 02, Issue 01, pp. 17-22

[5] Rata V., Rusu L., 2020, Impact on Air Quality of the Offshore-Ships Operating in the Black Sea Maritime Borders of Romania, Journal of Environmental Protection and Ecology, 21(1), pp. 19-27.

[6] Iticescu C., Murariu G., Georgescu L.P., Burada A., T.opa C.M., 2016. Seasonal variation of the physico-chemical parameters and Water Quality Index (WQI) of Danube water in the transborder Lower Danube area, Rev. de Chimie 67(9), p. 1843 1849.

[7] WIKIPEDIA. Available online: https://en.wikipedia.org/ (accessed in May 2020)

[8] Skolka M., Preda C.,2011, Alien invasive species at the Romanian Black Sea coast-Present and perspectives. Travaux du Muséum National d'Histoire Naturelle "Grigore Antipa», 53, pp. 443467.

[9] Shiganova T.A., 1998, Invasion of the Black Sea by the ctenophore Mnemiopsis leidyi and recent changes in pelagic community structure, Fish. Oceanogr, 7, pp. 305-310.

[10] Oral M., 2010, Alien fish species in the Mediterranean-Black Sea Basin. J. Black Sea/Mediterr. Environ., 16, pp. 87-132.

[11] Shiganova T., 2011, Ponto-Caspian: Invasions, Encyclopedia of Biological Invasions, 3rd ed., Encyclopedia of the Natural World, No. 3, Simberloff, D., Rejmanek, M., Eds., University of California Press, Berkeley/Los Angeles, CA, USA, pp. 549-556
[12] Jernelöv A., 2017, The Warty Comb Jelly in the Black Sea, The Long-Term Fate of Invasive Species; Springer: Cham, Switzerland, 2017; pp. 261-278.

[13] Riisgard H.U., Goldstein J., 2014, Jellyfish and ctenophores in limfjorden (Denmark)-MiniReview-with recent new observations. Journal of Marine Science and Engineering, 2, pp. 593-615.

[14] Microsensor. Available online: https://www.microsensorcorp.de/pressure-and-leveltransmitter-applied-in-ship-s-ballast-tank (accessed in May 2020)

[15] Guide to Masters. Available online: http://www.bosphorusstrait.com (accessed in May 2020)

[16] Google Earth Application

[17] Alkan G.B., Satir T., 2005, Ballast water problem in the Black Sea and Turkish straits, Proceedings of the 13 International Symposium,

Thessaloniki, Greece, 8-12 October 2005

[18] North-Western Shipping Company. Available online: http://www.nwship.com/en/ (accessed in June 2020).

[19] American Bureau of Shipping register. Available online: https://www.eagle.org/ portal/\#/absrecord/ search (accessed in May 2020) [20] Weight of Grain Wheat. Available online: https://www.aqua-calc.com/calculate/volume-toweight/substance /grain-blank-wheat (accessed in June 2020)

[21] LPG (propane) Gas Unit Conversions. Available online: https://www.elgas.com.au/blog/389-lpg-conversions$\mathrm{kg}$-litres-mj-kwh-and-m3 (accessed in June 2020) [22] Over 41,000 vessels pass through Bosphorus in 2019. Available online:

https://www.aa.com.tr/en/economy/over-41-000vessels-pass-through-bosphorus-in-2019/1722573 (accessed in May 2020)

[23] Rata V., Hobjila A., Rusu L. 2019, LNG to Power in the Romanian port of Constanta, E3S Web of Confer-ences 103, 01007, ICACER 2019, pp. 1-5

[24] Annual Report, Port of Constanta, 2019. Available online: http://www.portofconstantza.com (accessed in June 2020)

[25] David M., Gollasch S., Leppäkoski E., 2013, Risk assessment for exemptions from ballast water management-the Baltic Sea case study, Mar. Pollut. Bull., 75, pp. 205-217

[26] International Maritime Organization, International Convention for the Control and Management of Ships' Ballast Water and Sediments, 2004. Available online: http://www.imo.org/en/About/Conventions/ ListOfConventions (accessed in June 2020)

[27] MEPC 71 agrees to implementation dates for ballast water treatment systems. Available online: https://www.dnvgl.com/news/mepc-71-agrees-toimplementation-dates-for-ballast-water-treatmentsystems-96659\#: :text=The $\% 20 \mathrm{MEPC} \% 2 \mathrm{C} \% 20$ at $\%$ 20 its $\% 2071$ st,agreement $\% 20$ will $\% 20$ have $\% 20$ global\%20impact. (accessed in June 2020) 